\title{
ESTRATÉGIAS EM DESIGN CERÂMICO: DO DESIGN EXPERIMENTAL E DE AUTORIA AO DESIGN INDUSTRIAL - PORTUGAL
}

STRATEGIES IN CERAMIC DESIGN: FROM EXPERIMENTAL DESIGN AND AUTHORSHIP TO INDUSTRIAL DESIGN - PORTUGAL

José Manuel C. B. C. Frade, Dr. (ESAD - Portugal) Josiane Wanderlinde Vieira, Dra. (UFSC)

\section{Palavras Chave}

Design, Cerâmica, Estratégia, Auto-produção, Ecodesign, Indústria

\section{Key Words}

Design, Ceramics, Strategy, Self-production, Ecodesign, Industry

\section{RESUMO}

Neste artigo é apresentada e discutida uma seleção de projetos de design recentemente desenvolvidos em Portugal em ambiente acadêmico que põem em evidência diferentes estratégias de design: design de autor em combinação com auto-produção, design experimental em combinação com o ecodesign e em parceria com uma empresa industrial cerâmica e design industrial.

\section{ABSTRACT}

This article presents and discusses a selection of design projects recently developed in Portugal in an academic environment that shows different design strategies: author design in combination with self-production, experimental design in combination with ecodesign and in partnership with a ceramics company and industrial design. 


\section{INTRODUÇÃO}

Com a globalização, onde os negócios, os mercados e os fabricantes operam à escala global, é evidente que o setor industrial cerâmico só tem sustentabilidade se conseguir se diferenciar pela inovação ou pelo design. A competição pelo preço está fora de questão, porque haverá sempre alguém que produzirá a um custo mais baixo do que os custos de referência portuguesa [1].

Os materiais cerâmicos abrangem um largo espectro de materiais que vão desde os cerâmicos técnicos, de engenharia ou especiais, até à utilização deste material em artes plásticas [2]. Entre estes dois limites técnicos e artísticos, os graus de liberdade com que designers podem trabalhar é necessariamente diferente.

O projeto de produtos no âmbito da cerâmica técnica tem que se orientar fundamentalmente para o cumprimento de requisitos que se relacionam em primeiro lugar com o cumprimento eficaz dos requisitos funcionais, enquanto a cerâmica artística experimenta muitas vezes os limites da liberdade formal do material. 0 design de produtos cerâmicos industriais tradicionais está enquadrado dentro destes dois tipos limite de design.

Este artigo procura mostrar as principais linhas estratégicas de design de produtos cerâmicos no sistema de ensino superior português, especificamente na Escola Superior de Artes e Design de Caldas da Rainha, do Instituto Politécnico de Leria, considerada uma referência nacional, cujos cursos de design estão incluídos dentro das melhores escolas de design da Europa [3]. Para o efeito é apresentada uma seleção de projetos de design de produto cerâmico, desenvolvidos recentemente, e realizada uma discussão abordando as principais estratégias que se evidenciam em cada trabalho.

\section{APRESENTAÇÃO DE PROJETOS EDISCUSSÃO}

Em primeiro lugar apresenta-se o projeto Moldes Mutantes, um trabalho de Vitor Agostinho, realizado no âmbito do curso de mestrado em design de produto (ESAD.CR) [4].

O trabalho Moldes Mutantes é uma abordagem experimental inserida nos processos de conformação cerâmica e num universo de auto-produção, orientado pelos professores Fernando Brízio e José Frade.

Tal como neste trabalho, o fenômeno da auto-produção tem-se destacado e vem sendo cada vez mais utilizado pelos designers, que não se sentem totalmente identificados ou integrados no âmbito industrial. A aproximação dos designers à produção, mais do que um simples exercício exploratório, é uma nova forma de criar, que permite abrir um conjunto de novas possibilidades para o futuro.

Neste trabalho foram desenvolvidas três estratégias de conformação cerâmica de objetos que permitem variação de forma ou dimensão a partir de um mesmo molde:

- construção de moldes através de uma combinação/ sobreposição controlada ou aleatória de blocos de gesso cúbicos (modelos), facetados numa ou duas faces com ângulos de 15, 30 e 45 graus (Figura 1), com a possibilidade de conjugação deste princípio com a reutilização de moldes em fim de vida de outros produtos (Figura 2);

Figura 01 - Produtos cerâmicos obtidos a partir de uma combinação/ sobreposição de cubos em gesso.

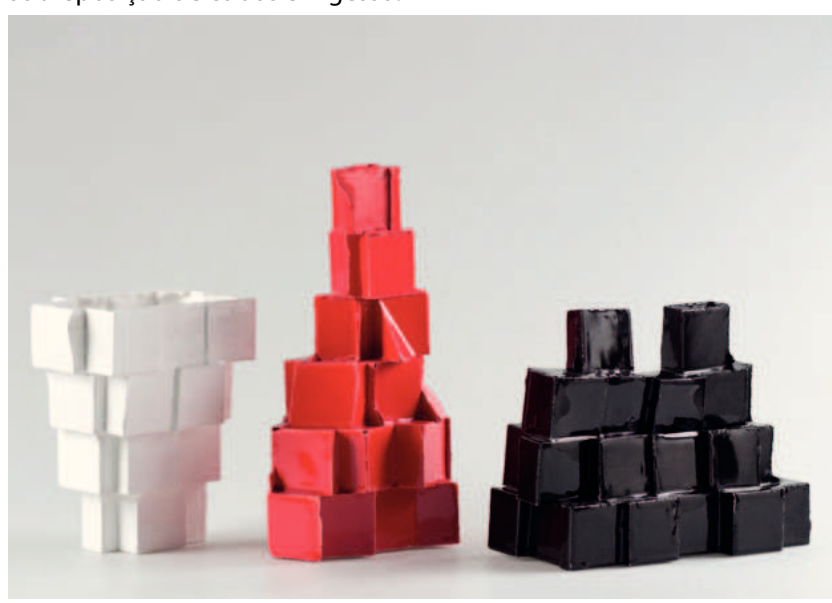

Fonte: Vitor Agostinho

Figura 02 - Produto cerâmico obtido pela conjugação do processo referido na Figura 1 com a reutilização de moldes em fim de vida de produtos industriais.

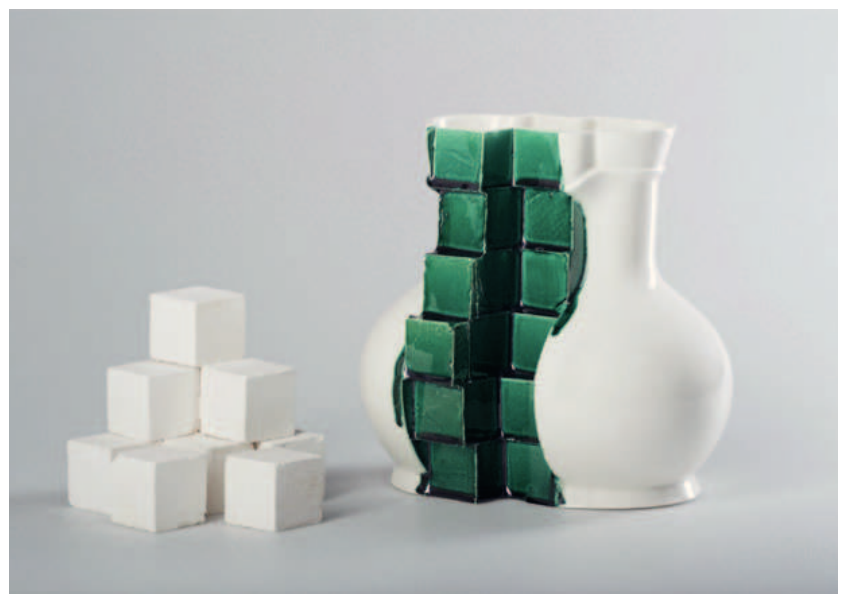

Fonte: Vitor Agostinho 
- construção de moldes constituídos por elementos de repetição (modelos) ligados entre si por um material têxtil, de modo a tornar possível a articulação e flexibilidade tridimensional da superfície (Figura 3);

Figura 03 - Moldes de gesso multipartes articulados através de um sistema de ligação têxtil e respectivos produtos cerâmicos conformados com estes moldes.

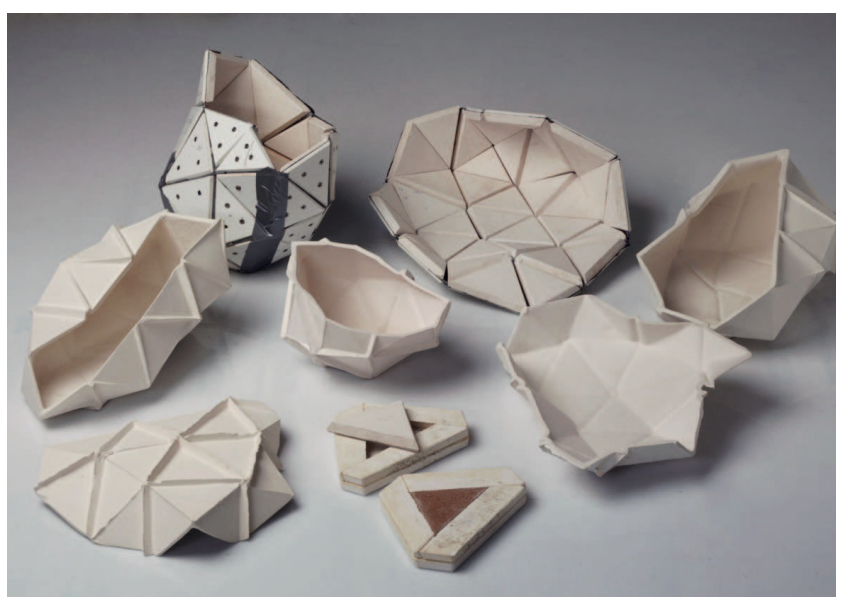

Fonte: Vitor Agostinho

- construção de moldes com sistema de ligações, nas suas várias partes, que permitem inúmeras reconfigurações a partir de qualquer movimento de uma parte com efeito na alteração da posição dos demais elementos do mesmo molde (Figura 4), permitindo uma diversidade de configurações moldantes a partir de um único molde.

Figura 04 - Moldes de gesso multipartes articulados com elásticos e respectivos produtos cerâmicos conformados com estes moldes.

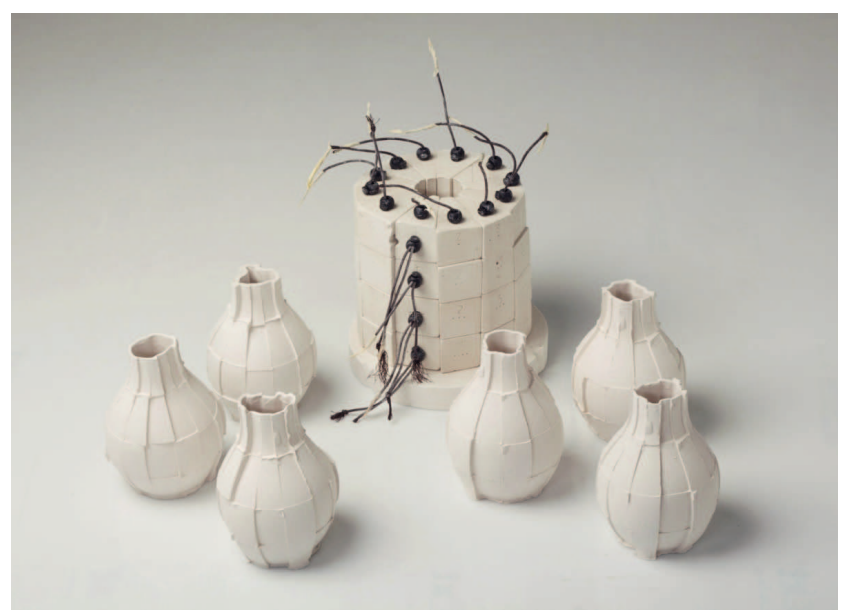

Fonte: Vitor Agostinho
Neste trabalho evidencia-se uma forte componente de experimentação tecnológica por parte do autor/designer, com resultados evidentes sobre as formas e superfícies dos produtos fundamentalmente decorativos ou artísticos. A auto-produção impõe, neste caso, o uso de tecnologias simples, de baixo custo, que conjuntamente com a criatividade inovadora do designer conduz a produtos únicos, ou pequenas séries, que contrariam o comum resultado de uma produção industrial. A cor dos vidrados e a vidragem manual reforçam a estratégia de diferenciação entre produtos, distanciando-os ainda mais do tipo padrão de um produto cerâmico produzido industrialmente. $\mathrm{O}$ uso da reutilização de moldes industriais revela uma consciência ambiental. Neste caso é importante que o designer tenha competências adicionais na área da comunicação, gestão, marketing e comercialização, de forma a facilitar a condução das suas produções para o mercado.

Em segundo lugar apresenta-se o projeto Uroboro, um trabalho de Marco Balsinha [5], realizado no âmbito do curso de mestrado em design de produto (ESAD.CR) em parceria com a empresa Val do Sol, Cerâmicas S.A.

Este projeto teve como objetivo o design de um produto que contribua para a redução de resíduos urbanos biodegradáveis em aterros, direcionando-os com vantagem para vasos de plantas, nomeadamente aromáticas. O produto Uroboro permite a vermicompostagem em espaço doméstico, sem comprometer as condições de segurança, higiene e conforto dos respetivos utilizadores.

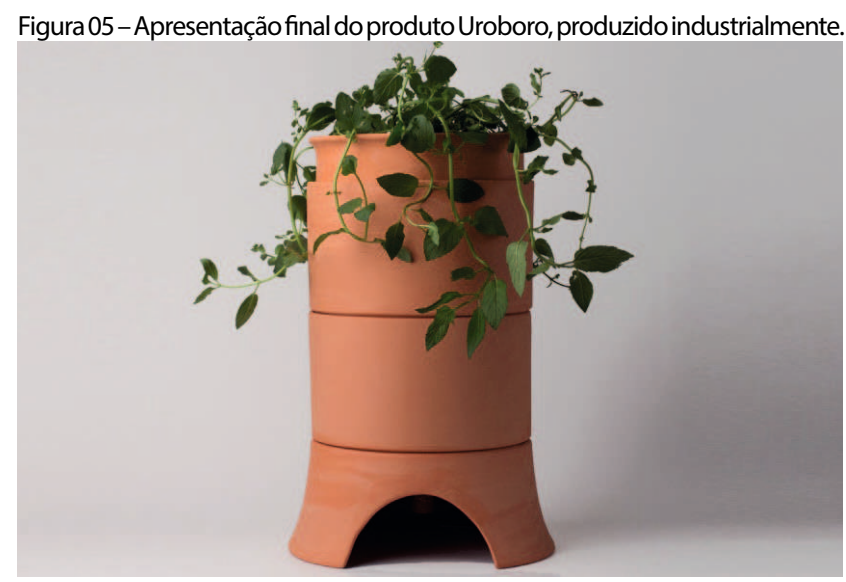

Fonte: Marco Balsinha

O uroboro é um sistema que se desenvolve num produto complexo, do tipo modular, constituído por 4 tipos de peças:

- Peça A, que é colocada no topo do produto com a função de vaso para plantas e que se desloca ao ritmo da degradação dos resíduos colocados nas peças 
situadas por baixo; esta peça não é vidrada na superfície inferior de modo a facilitar a troca de humidade entre o vaso ou contentor e a peça que Ihe fica imediatamente por baixo.

- Peça(s) B com a função de reservatórios ou contentores do sistema de vermicompostagem; o utilizador decide o número de peças deste tipo que por encaixe vão fazer parte do seu sistema e por isso decide a capacidade de vermicompostagem do seu produto; estas peças não têm fundo e por isso permitem a circulação das minhocas no sistema, sempre que necessário o utilizador deve retirar o composto destas peças para vasos de plantas.

- Peça C, colocada na zona inferior do conjunto das peça(s) $B$, com a função de coletor da água que resulta do processo de vermicompostagem, ou mesmo de um excesso de água que seja utilizado na rega da planta; não é vidrada na parte superior, para facilitar a circulação de água por gravidade, é vidrada na parte inferior para impermeabilizar nesta zona o sistema, e tem uma abertura, para colocação de um sistema de vedação removível (neste caso uma rolha de cortiça) para fazer a extração da água para fora do sistema.

- Peça D, com a função de suporte da totalidade das peças do conjunto, com abertura para colocação de reservatório externo para recolha de água da peça colocada imediatamente acima (peça C).

Figura 06 - Desenho técnico do produto (processo) uroboro com indicação dos diferentes níveis de composto e disposição das diferentes peças.

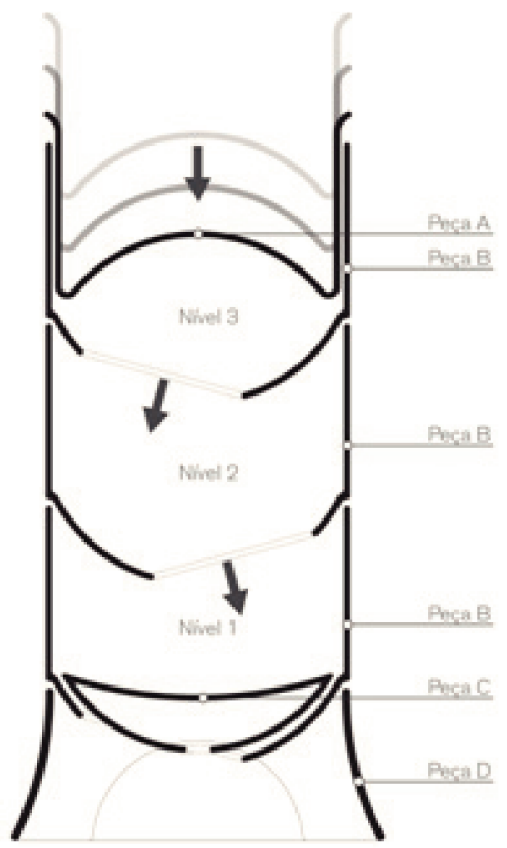

Fonte: Marco Balsinha
Foi selecionado o barro vermelho para materializar este produto por razões funcionais e estratégicas. Funcionalmente, o barro vermelho industrial, coze a temperaturas relativamente mais baixas do que outras pastas cerâmicas industriais, compatíveis com maiores porosidades nos produtos de barro vermelho, o que é importante para o sistema de vermicompostagem, dada a necessidade por um lado de permeabilidade de água entre as várias peças do produto e por outro lado a oxigenação dos contentores de vermicompostagem, o que se consegue pela não vidragem de determinadas partes das peças $A, B$ e $C$ do vermicompostor cerâmico doméstico. Estrategicamente, o barro vermelho, reforça o caráter sustentável deste produto, pela sua maior disponibilidade relativa, menor temperatura de cozedura e consequentemente gera menores emissões gasosas durante todo o processamento industrial.

Um decalque introduzido na superfície da peça $A$ (Figura 7), pretende aumentar a interface de comunicação entre o estado do sistema e o utilizador. O grafismo do decalque e o posicionamento relativo da peça $A$ no sistema em função da decomposição por vermicompostagem de resíduos que ocorrem nas peças $B$, pretende indicar se deve ser adicionado mais resíduos ao sistema para serem convertidos em composto de vermicompostagem.

Figura 07 - Detalhe da colocação do decalque na peça $A$ e do encaixe da peça A sobre uma peça $B$.

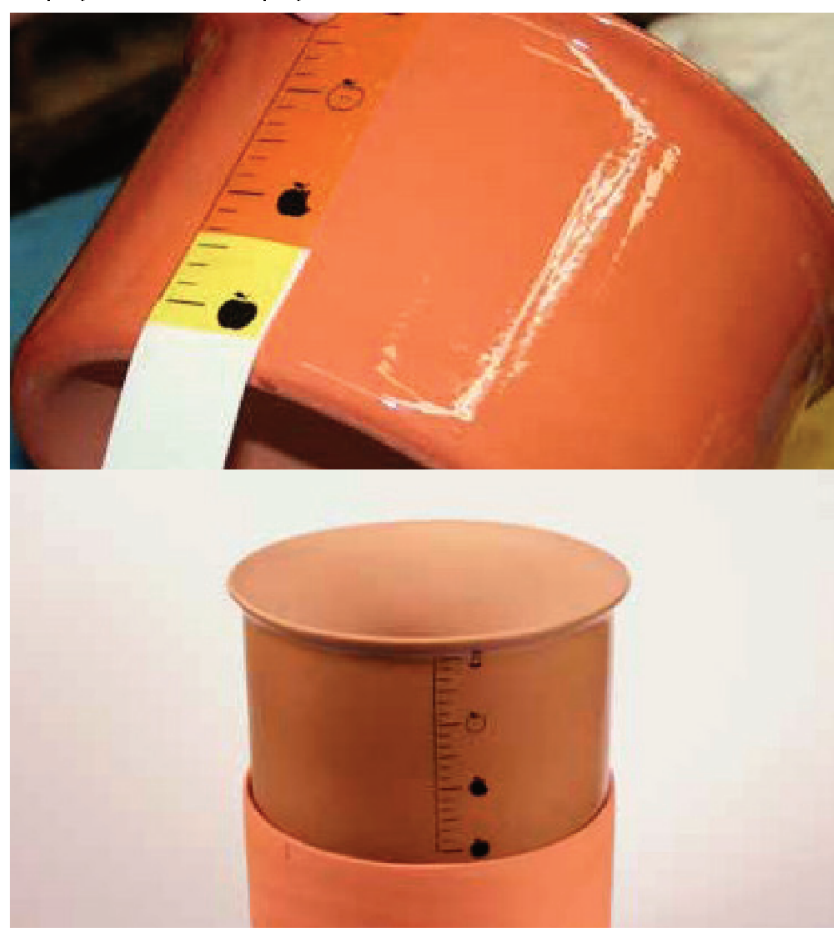

Fonte: Marco Balsinha 
Uma particularidade estratégica deste projeto de design foi a sua realização em parceria com uma empresa industrial portuguesa do setor cerâmico utilitário e decorativo de barro vermelho. Nas Figuras 8 a 12 apresentam-se imagens das peças em produção, no âmbito do circuito industrial.

Figura 08 - Vidragem da peça $A$.

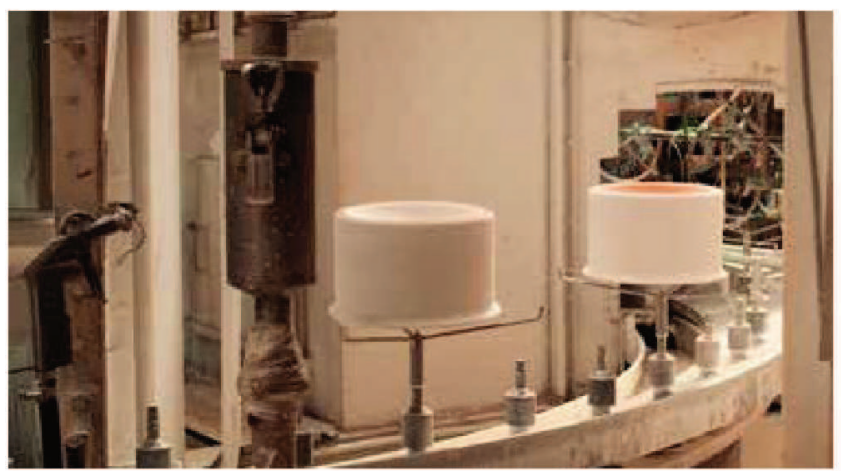

Fonte: Marco Balsinha [5].

Figura 09 - Peça B, tal qual saída do molde de gesso (lado esquerdo), com acabamentos finais conforme projeto, após conformação (lado direito).

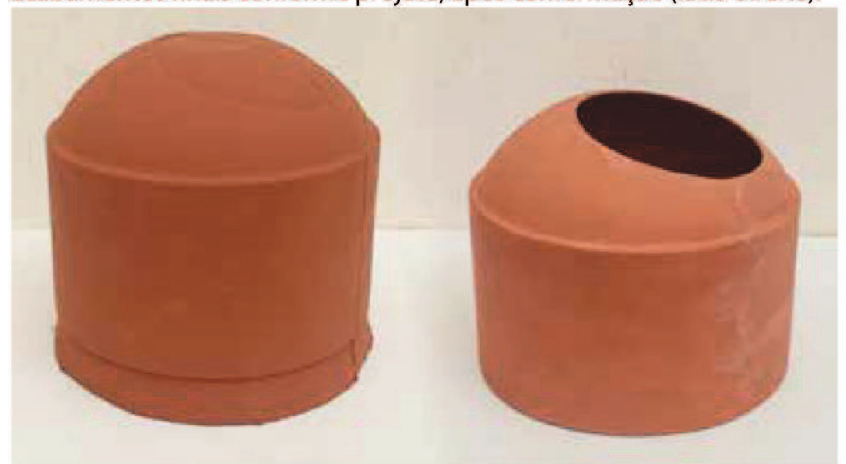

Fonte: Marco Balsinha

Figura 10 - Vagonetes dos fornos de cozedura, com os sistemas pré-montados para maior controle da estabilidade dimensional entre as várias peças de cada produto.

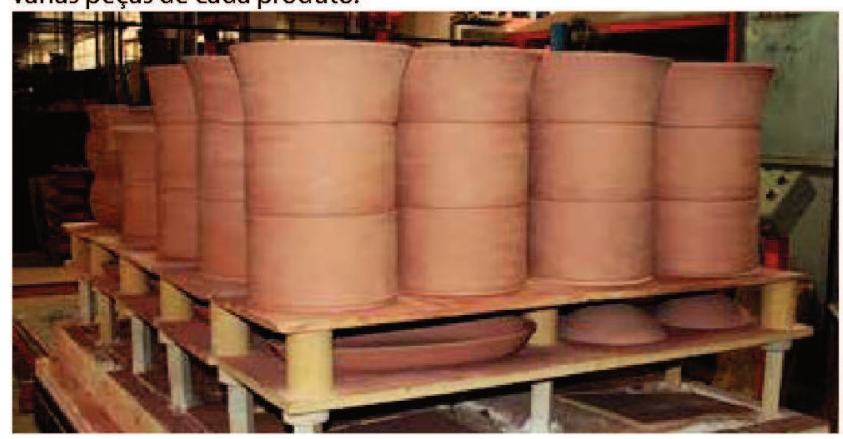

Fonte: Marco Balsinha
Figura 11 - Peças A (parcialmente vidrada) e B (não vidrada), com evidência do detalhe do desenho para encaixe, após cozedura.
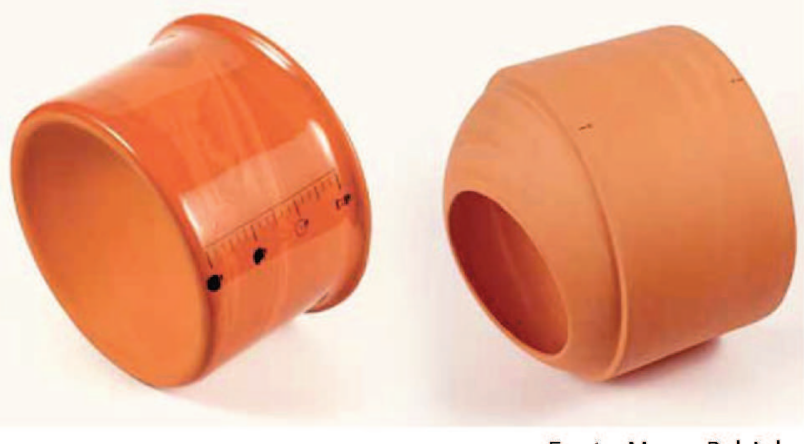

Fonte: Marco Balsinha

Figura 12 - Peças D (não vidrada) e C (parcialmente vidrada), após cozedura.
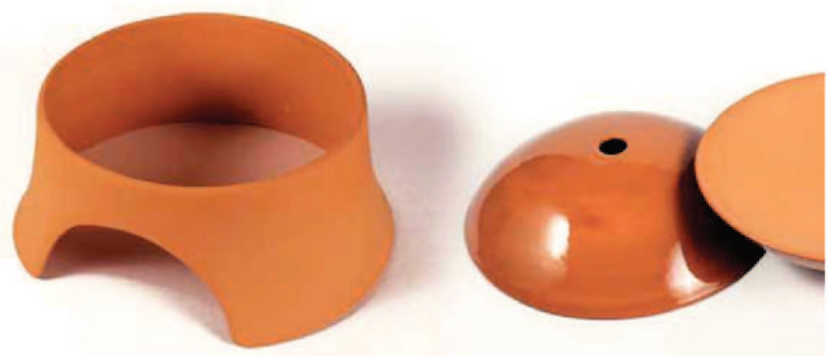

Fonte: Marco Balsinha

Este projeto integrou um conjunto de testes dos primeiros produtos finais que confirmaram o funcionamento de todo o sistema de vermicompostagem, sem libertação de cheiros para o espaço doméstico, e com potencial educacional no âmbito da consciência social e ambiental, Figuras 13 e 14, respectivamente.

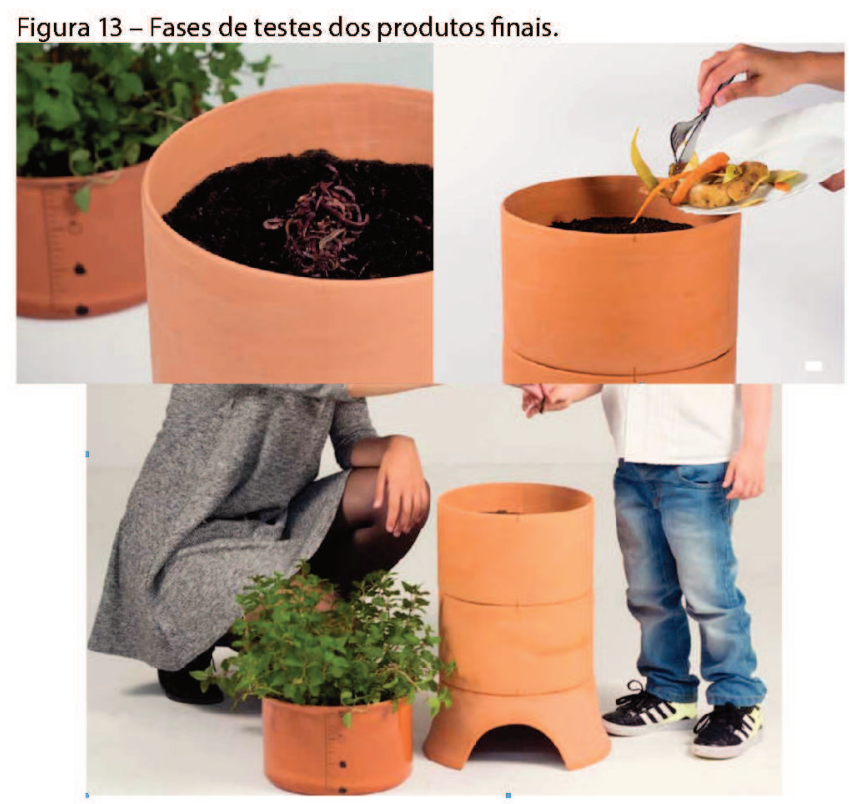

Fonte: Marco Balsinha 
Debates relacionados com a sustentabilidade ambiental e econômica têm colocado a disciplina do design num plano estratégico industrial e econômico como recurso para o desenvolvimento de produtos inovadores e que respondam diretamente a estas questões ambientais, sociais e econômicas. É evidente que este projeto foi conduzido principalmente por uma estratégia de eco-design, com desenhos que tiveram que se compatibilizar a todo o momento com a tecnologia industrial da empresa parceira, e com a empresa a distanciar-se neste projeto de um processo mais automatizado, no sentido de uma maior inclusão de trabaIho manual na conformação das várias peças (desvidragem da peça $A$; corte no fundo peça $B$, abertura para vedante removível na peça $C$, corte na peça $D$, para acesso à peça $C$ ), o que não é comum verificar em empresas industriais. Este projeto tem duas valias comerciais importantes:

- construção modular (convidando à aquisição de várias peças para a construção do produto)

- posicionamento da empresa em novos mercados emergentes (direcionados para a responsabilidade social e ambiental), para além do clássico mercado da louça utilitária e decorativa.

Por último apresenta-se um projeto que foi desenvolvido num tempo mais curto (apenas 30 horas), por Joana Barros, na unidade curricular de Seminário Transdisciplinar do Curso de Mestrado em Design de Produto, orientado pelo professor José Frade, que visa o design de produtos cerâmicos industriais inovadores. Dado o tempo exíguo para este trabalho, optou-se por estrategicamente estudar produtos de porcelana, de empresas de referência portuguesa, tendo-se para o efeito realizado uma visita de estudo à empresa Vista Alegre, à zona industrial, "showroom" e zona comercial (loja da fábrica) e estudado tendências recentes e catálogos de produtos disponíveis na internet [6-8]. As ferramentas de desenhos computacionais, 2D e 3 D, nomeadamente o software "Solidworks" foi a principal ferramenta usada neste projeto. Assumiu-se que o aluno não tinha que ter competências de produção propriamente ditas, mas que tinha que perceber a compatibilidade entre os desenhos das suas propostas e a possibilidade de serem executados industrialmente com as tecnologias e materiais disponíveis numa típica empresa industrial de porcelana. Decidiu-se, ainda, pesquisar e estudar o catálogo dos produtos de empresas de referencia no sentido de procurar oportunidades para o design de novos produtos atendendo por um lado às tendências e comportamentos de consumo mais atuais deste material, e por outro lado, propondo na medida do possível, produtos de certo modo inovadores dentro do portifólio dos produtos existentes, não esquecendo uma análise crítica, ainda que elementar, do potencial comercial dos mesmos. Neste sentido, foi desenvolvida uma proposta de um conjunto de produtos cerâmicos decorativos de diferentes alturas e diâmetros que têm a particularidade de se poderem encaixar uns nos outros, ou seja colocar uns dentro dos outros, oferecendo ao usuário a liberdade de disposição que melhor the parecer quando os usar nos mais diferentes ambientes. Criaramse linhas diferentes dentro destes produtos, diferenciadas através da cor. A conformação exige moldes de gesso relativamente simples para enchimento por via líquida, a vidragem das peças monocromáticos será automática e as peças com mais de uma cor podem ser conseguidas através de vidragem ou pintura manual.

Figura 14 - Coleção de produtos em porcelana, com vidrado transparente.

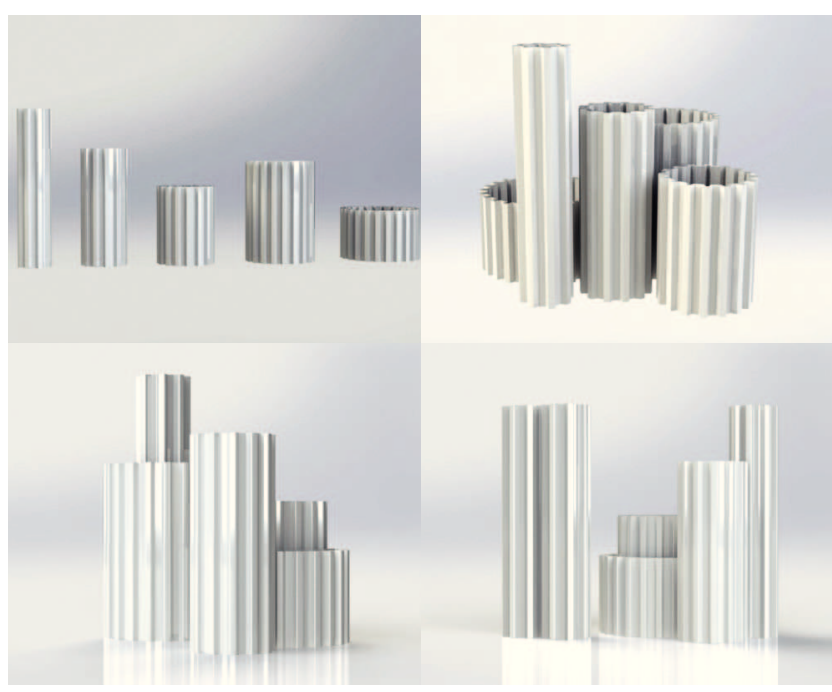

Fonte: Joana Barros.

Figura 15 - Disposição de produtos de porcelana da coleção azul, combinadas com uma peça da linha vidrada a transparente.

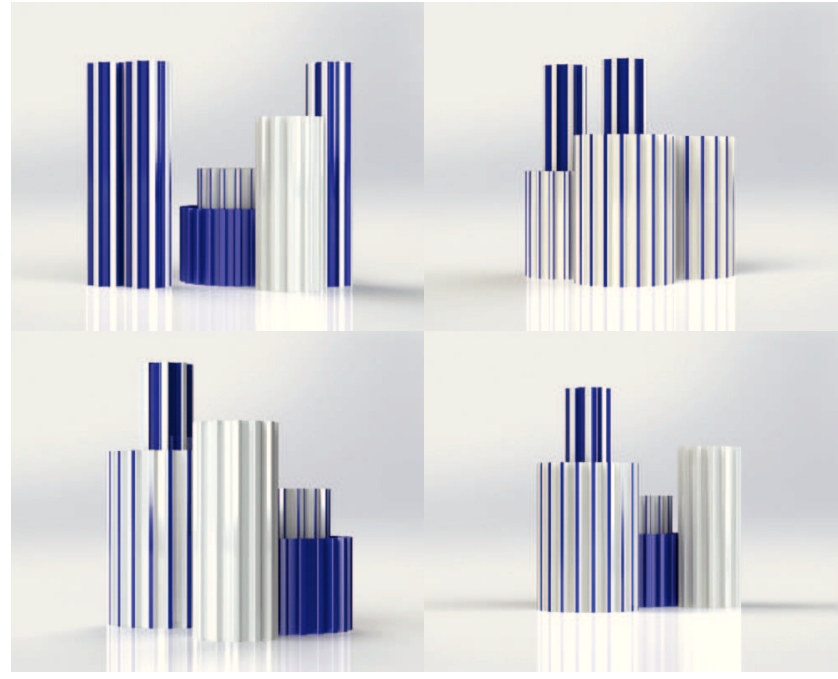




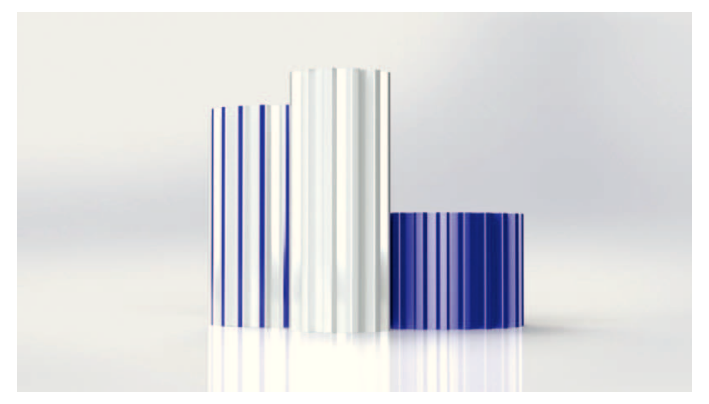

Fonte: Joana Barros.

Figura 16 - Disposição de produtos de porcelana da coleção verde, cinza e vidrada a transparente.

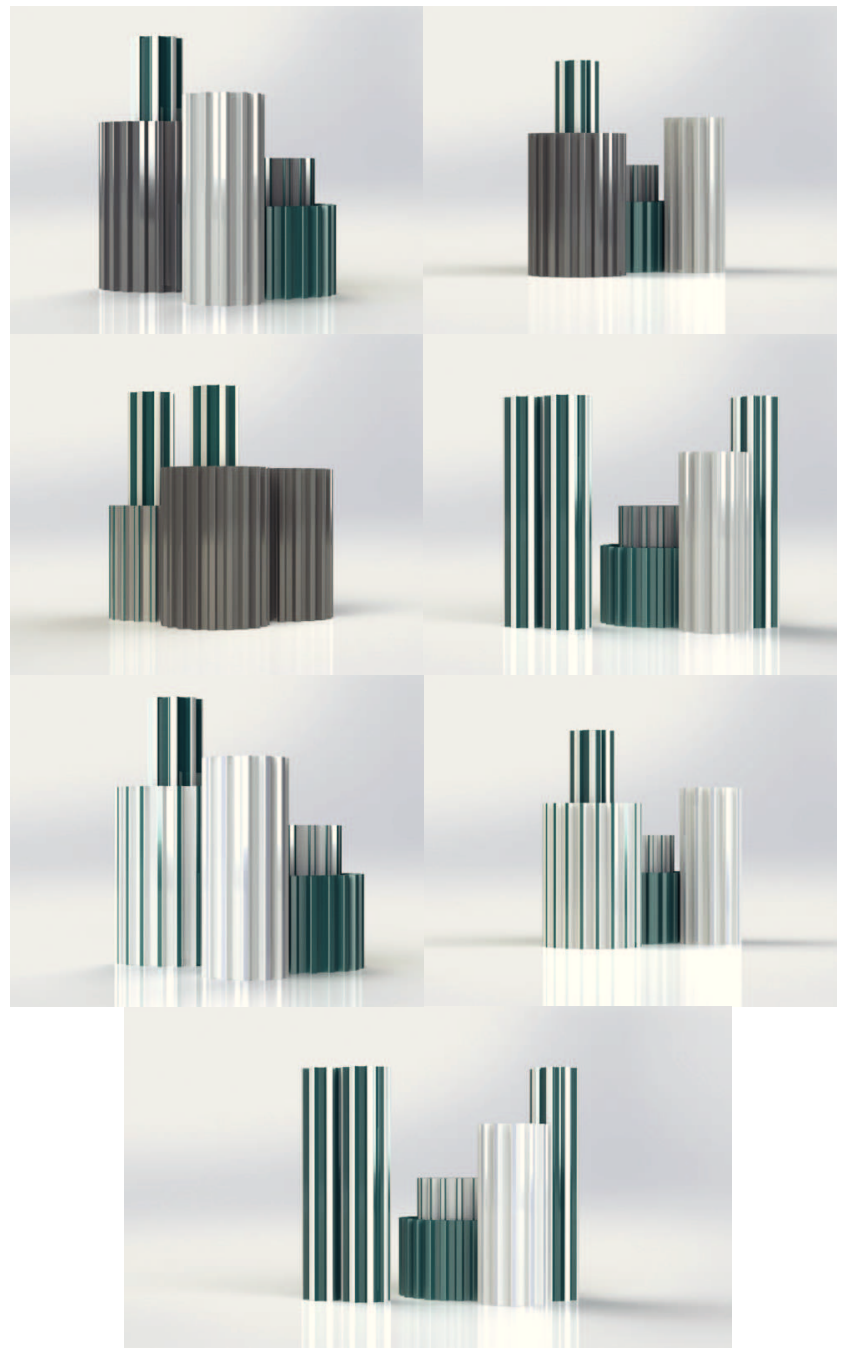

Fonte: Joana Barros.

\section{CONCLUSÕES}

Nos três casos apresentados e discutidos evidenciam-se diferentes estratégias no projeto de design de produtos cerâmicos.

As estratégias de projeto de design que assentam em projetos de auto-produção (primeiro caso de estudo) conduzem normalmente para produtos mais artísticos, onde o projeto de design combina muitas vezes o design de produto e o design de processos - na maioria das situações de baixa complexidade. A experimentação criativa ao nível dos processos de produção podem ser uma fonte de diferenciação deste tipo de produtos cerâmicos.

No segundo caso de estudo é evidente que a consciência e a responsabilidade social e ambiental do designer conduziu o projeto de design. Por outro lado, a parceria com a empresa obrigou a uma permanente compatibilização do desenho com as tecnologias industriais disponíveis para a materialização do produto cerâmico e fomentou uma preocupação do potencial estratégico comercial deste produto cerâmico (compostor doméstico). Este projeto culminou com um eco-produto industrial cerâmico com elevado potencial pedagógico e de alerta para a consciência ambiental da sociedade.

Finalmente no terceiro caso de estudo, evidenciou-se a importância das ferramentas de desenho 3D na realização de projetos de design em tempos relativamente mais curtos. Neste caso não houve necessidade de realizar protótipos físicos, nem é exigível uma particular especialização no domínio do saber fazer tecnológico.

A relação direta entre um baixo tempo de execução de um projeto com (i) a produtividade dos gabinetes de design, (ii) a redução de custos associados ao design de novos produtos e o (iii) curto tempo de vida dos produtos nos mercados (que exigem muitas vezes substituições rápidas para manutenção das respectivas cotas de mercado), parece justificar que seja esta a metodologia de projeto mais presente nos departamentos de design industriais. Esta estratégia obriga, entre outros, a um conhecimento profundo dos mercados, das tendências e comportamentos de consumo, dos limites tecnológicos e materiais de cada realidade industrial, para uma desejável assertividade nas propostas de design com a futura execução material dos mesmos. Projetos realizados em tempos curtos, que respondam ao desejo dos consumidores, e que sejam produzidos facilmente com os materiais e tecnologias disponíveis a cada momento, contribuem positivamente para a sustentabilidade económica, social e ambiental das empresas e das sociedades.

Nos três casos de estudo é evidente um certo foco em termos de sustentabilidade, ou porque os projetos contribuem para a própria empregabilidade, ou porque disponibilizam novos produtos que contribuem favoravelmente para a ecologia e para a consciência ambiental das comunidades ou ainda por contribuirem para a sustentabilidade industrial, com desejável impacto positivo sobre a economia e as condições sociais do país. 
Finalmente importa concluir que o projeto de design de produtos cerâmicos técnicos é ainda uma oportunidade para ser explorada na área do design cerâmico. A elevada complexidade funcional e de processo associada a estes produtos, abre perspectiva de metodologias de ensino a partir de equipes multidisciplinares de design que integrem pelo menos designers e engenheiros - eventualmente de mais do que uma área da engenharia - o que ainda não é uma realidade em Portugal.

Num futuro trabalho, pretende-se fazer a análise crítica do ponto de situação comercial de cada um destes três projetos.

\section{REFERÊNCIAS}

ASHBY, Michaele e JOHNSON, Kara; Materials and Design: The Art and Science of Material Selection in Product Design; 3a Ed.; (2013).

AGOSTINHO, Vitor; Moldes Mutantes para cerâmica e vidro; Tese de Mestrado; ESAD.CR; (2013).

BALSINHA, Marco; Uruboro (compostor cerâmico); Tese de Mestrado; ESAD.CR; (2015).

Catálogo Vista Alegre; http://www.go-menu.pt/images/galeria/160114111737_626965.pdf; (3/2017).

Catálogos SPAL; http://www.spal.pt/index.php/catalogos; (3/2017).

FRADE, José; Inovação e Design; Cerâmica Portuguesa tradição e inovação; pág 94-95; Edição APICER - Associação Portuguesa das Indústrias de Cerâmica e Vidro; 2016.

Loja virtual Vista Alegre; https://vistaalegre.com/pt/c/ bestsellers-pt $/$ Cat $=19365 \&$ Specs $=\&$ PageSize $=48 \& \mathrm{Page}=$ 1\&PriceL=0\&PriceH $=99999 \&$ ReturnProducts $=$ false $\&$ SelGr oups $=\&$ SelGrp=\&InStock=0; (3/2017).

Top 100 Escolas de arquitetura e Design da Europa; Domus magazine; (12/2014) 